\title{
Calcinosis of the Internal Juglar Vein: Interesting Presentation of Tertiary Hyperparathyroidism
}

\author{
Theodore Klug, MD, MPH', Mona Shete, $M D^{2}$, Courtney B Shires, MD, FACS ${ }^{1}$ \\ ${ }^{1}$ West Cancer Center, TN, USA \\ ${ }^{2}$ Shete ENT, TN, USA
}

\begin{abstract}
Background: Tumoral calcinosis is an uncommon but severe complication of hemodialysis therapy as a result of high calcium and phosphorus products. Tumoral calcinosis is a known entity following dialysis, with deposition throughout the hands and hips, joints, shoulders and fingertips.

Case presentation: A 49-year-old male with history of dialysis due to end-stage renal disease (ESRD) reported pain in his left molars that increased to bilateral dentition. Computerized tomography (CT) was performed, revealing a large calcified lesion in the retropharyngeal area on the right side abutting the internal carotid artery. Conservative observation was recommended. He represented 3-years later with stridor. CT of the neck with contrast showed an amorphous calcific soft tissue deposition mass lesion extending from the right posterior pharyngeal aspect to the thyroid lamina with saber-like narrowing of the upper airway. The calcified mass was significantly larger than it was 3-years earlier. Modified barium swallow test showed aspiration. Fine needle aspirate of the neck mass revealed calcium deposits. His stridor and dyspnea increased, and he required emergency awake tracheostomy placement. He had been noncompliant with dialysis for his chronic renal disease, and his parathyroid hormone (PTH) was 589.1. Calcium levels were also elevated. Surgical excision of the calcified internal jugular vein was discussed with the family. He is participating in rehabilitation so that he can withstand surgery in the future.
\end{abstract}

Conclusions: This is the first report of internal jugular vein calcinosis to our knowledge. Presentation included dental pain and airway obstruction. Surgical excision has been recommended, as this remains the primary method of treatment for calcinosis.

Keywords

Calcinosis, Internal Jugular Vein (IJV), Tracheostomy, Hyperparathyroidism

List of Abbreviations

ESRD: End-Stage Renal Disease; CT: Computerized Tomography; MRI: Magnetic Resonance Imaging; ICU: Intensive Care Unit; PTH: Parathyroid Hormone

\section{Background}

Tumoral calcinosis is an uncommon but severe complication of hemodialysis therapy [1]. The formation of tumoral calcification has been attributed to high calcium and phosphorus products after long-term dialysis [1]. There are multiple case reports of tumoral calcinosis following dialysis, with deposition throughout the hands and hips [1], joints [2], shoulders and fingertips [3], but never specifically in the internal jugular vein (IJV). This is the first case report we are aware of to this point.

\section{Case Presentation}

49-year-old male with history of dialysis due to end-stage renal disease (ESRD) that reported pain in his left molars in early November of 2017. He was treated with antibiotics by the health department and was referred to a dentist. The pain then shifted to the right-side molars. The patient also developed a sore throat on the right side. He then presented to a large municipal hospital on November 4, 2017, denying pain in his teeth but significant pain in his right jaw and throat.

*Corresponding author: Dr. Theodore Klug, MD, MPH, West Cancer Center, 7945 Wolf River Blvd, Germantown, TN 38104, USA, Tel: 901-683-0055

Accepted: November 18, 2020

Published online: November 20, 2020

Citation: Klug T, Shete M, Shires CB (2020) Calcinosis of the Internal Juglar Vein: Interesting Presentation of Tertiary Hyperparathyroidism. J Head Neck Surg 2(1):78-82 
Citation: Klug T, Shete M, Shires CB (2020) Calcinosis of the Internal Juglar Vein: Interesting Presentation of Tertiary Hyperparathyroidism. J Head Neck Surg 2(1):78-82

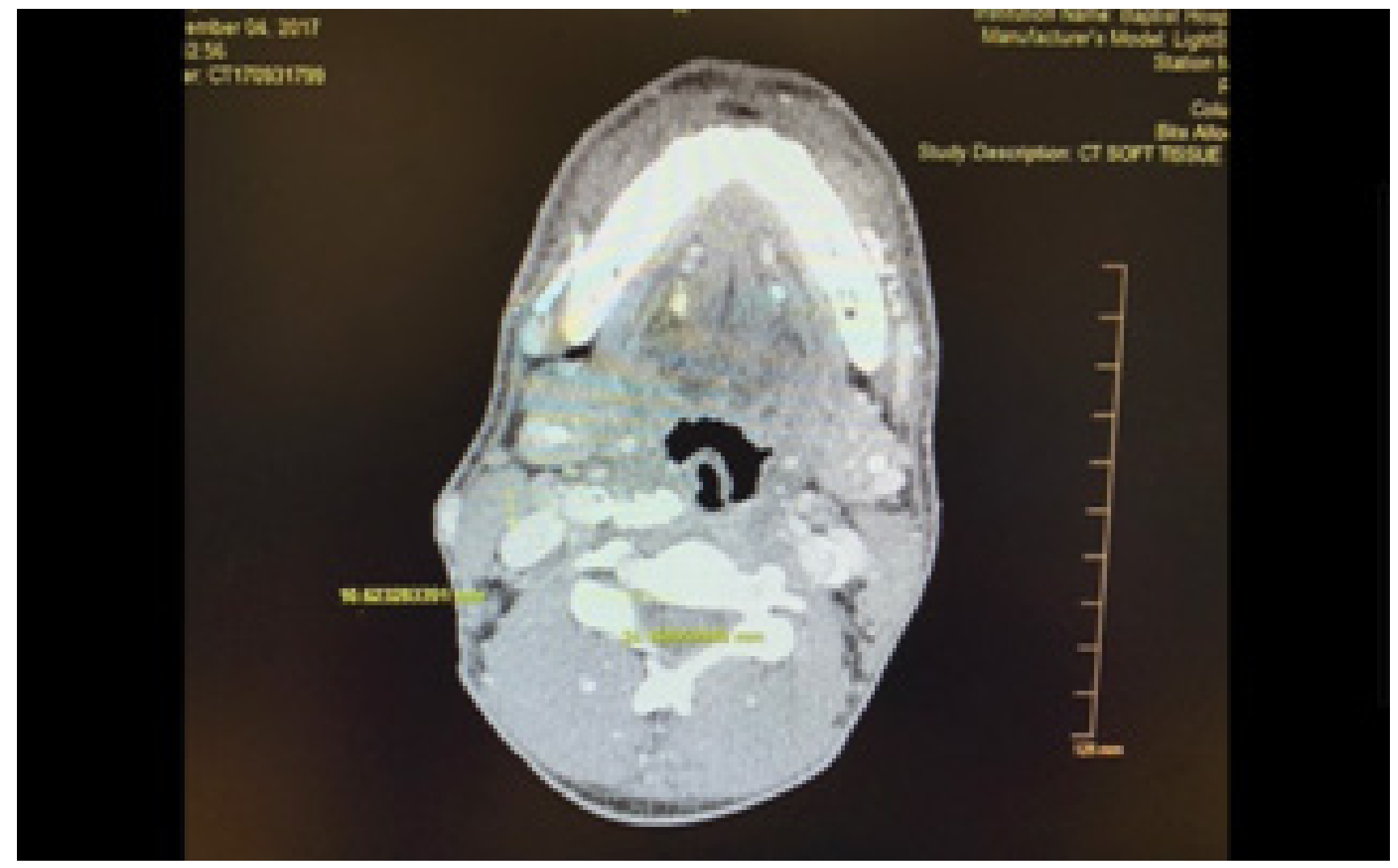

Figure 1: Axial view CT soft tissue neck. A large calcified lesion in the retropharyngeal area on the right side directly abutting the internal carotid artery.

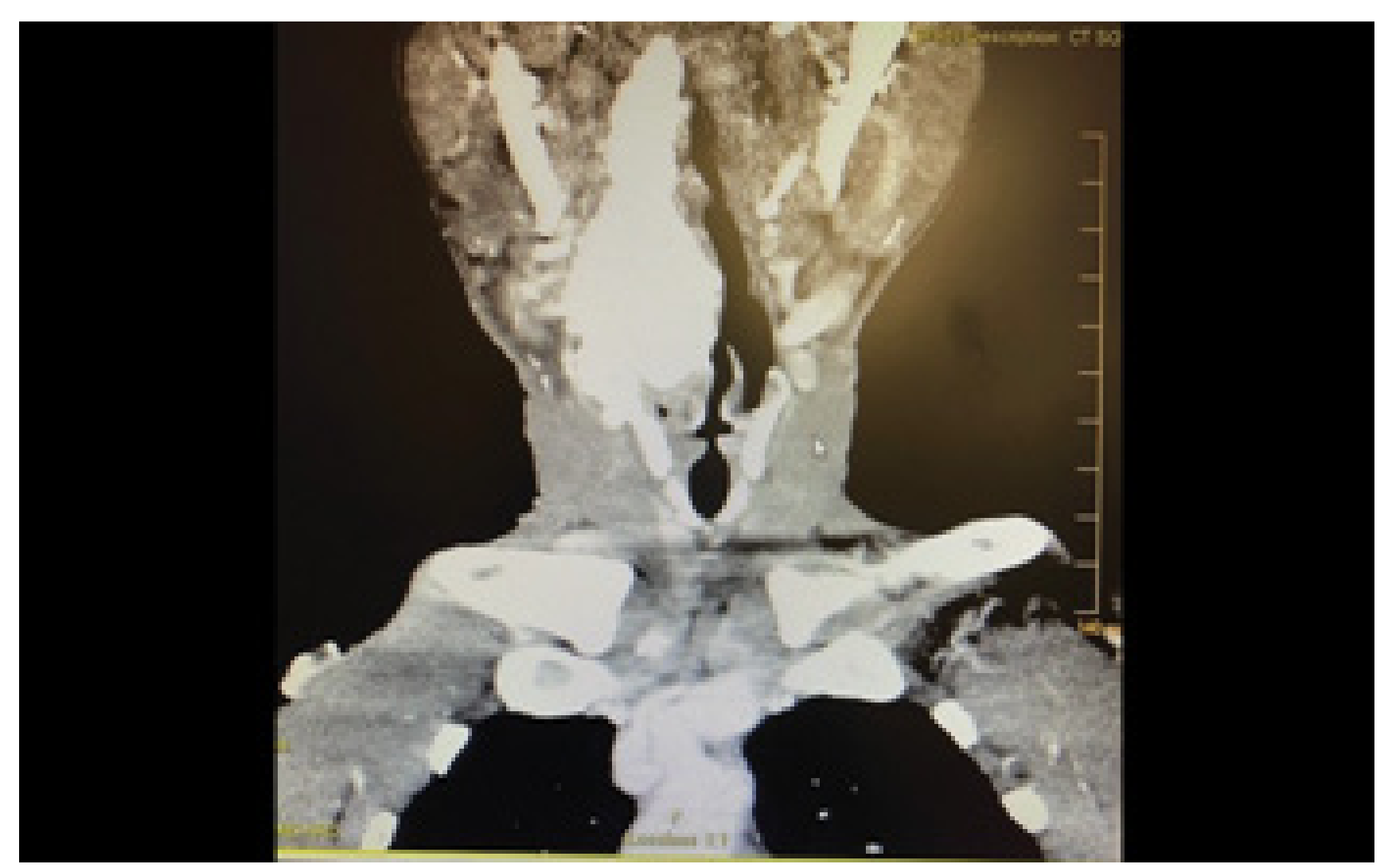

Figure 2: Coronal view CT with contrast neck. An amorphous calcific soft tissue deposition mass lesion. 
He denied fever and difficulty breathing at that time. Computerized tomography (CT) was performed, revealing a large calcified lesion in the retropharyngeal area on the right side directly abutting the internal carotid artery (Figure 1). There was no evidence of dental abscess, retropharyngeal abscess, peritonsillar phlegmon, or fluid collection. Conservative observation was recommended.

The patient did not present again until May of 2020. He complained of stridor upon presentation. CT of the chest with contrast was performed on May 11, 2020, showing mild pulmonary edema. CT of the neck with contrast was also performed that day, showing an amorphous calcific soft tissue deposition mass lesion extending from the right posterior pharyngeal aspect to the thyroid lamina with saber-like narrowing of the upper hypopharyngeal airway (Figure 2 and Figure 3). The size of the calcified mass was noted to be significantly increased relative to what was shown in 2017. Given the appearance on CT of a densely calcified or ossified mass, favored etiologies included metabolic causes for calcification and idiopathic tumoral calcinosis. An x-ray modified barium swallow test was performed on May 12 , showing aspiration. A magnetic resonance imaging (MRI) of the neck soft tissue only without contrast was also performed, showing a large, right-sided parapharyngeal mass extending laterally into the right-sided deep cervical soft tissues (Figure 4), corresponding with the large multilobulated calcified mass noted on recent CT (Figure 5).

The patient was admitted for stridor and increased difficulty with breathing. He was then transferred to the inten- sive care unit (ICU) following hypercapnia and a $\mathrm{CO} 2$ narcosis. CBCs and BMPs were drawn and trended, with adjustments made to improve an initial parathyroid hormone (PTH) of 589.1. Calcium levels were between 9.2 and 10.2 , while phosphorous levels remained normal throughout. Medicine, Otolaryngology, and Cardiothoracic Surgery were following the patient on a daily basis, until May 23, 2020, when an emergency tracheostomy had to be performed due to a compromised airway.

Past medical history for the patient includes ESRD, dialysis, thyroid disease, hemorrhoids, and hypertension. Past surgeries include abdominal surgery, colonoscopy, dialysis fistula creation, hernia repair, right AV graft ligation, and total thyroidectomy. The patient endorses alcohol use once or twice a month. No history of tobacco or drug use.

\section{Discussion and Conclusions}

Local trauma, chronic inflammation, and vascular hypoxia have been proposed as potential pathomechanisms for tumoral calcinosis [4]. Several therapies have been tried for calcinosis with variable results, but surgical excision of calcium deposits remains the primary method of treatment [4]. For our patient, there was no history of trauma. However, we believe his history of dialysis was the underlying mechanism behind his calcinosis. Previous studies have also shown that reduced patient compliance regarding dialysis treatment contribute to the aggravation of calcinosis in ESRD [5,6]. In turn, we postulate that the development of calcinosis in our patient is due to poor dialysis compliance. Still, we have no

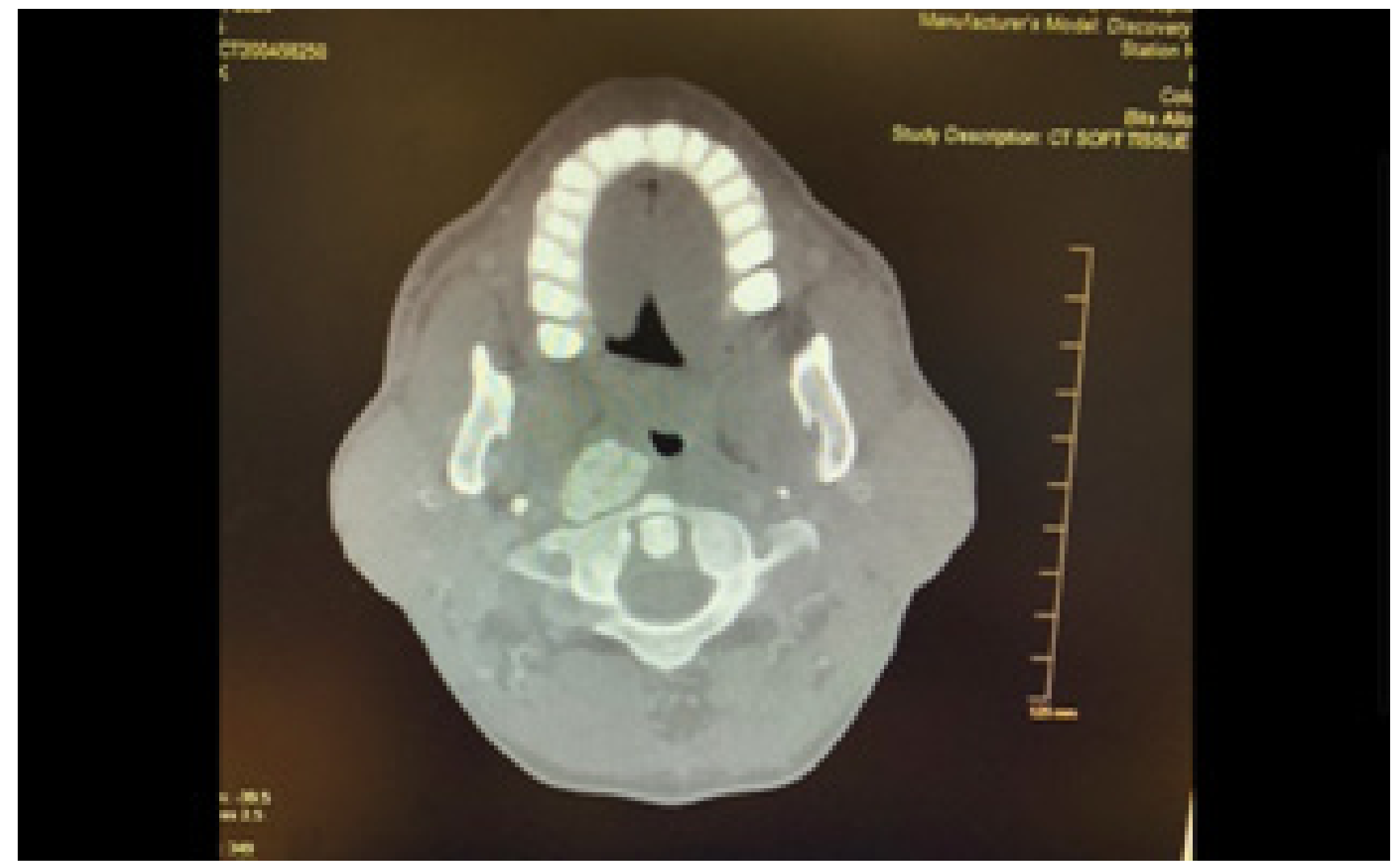

Figure 3: Axial view CT soft tissue. An amorphous calcific soft tissue deposition mass lesion. 


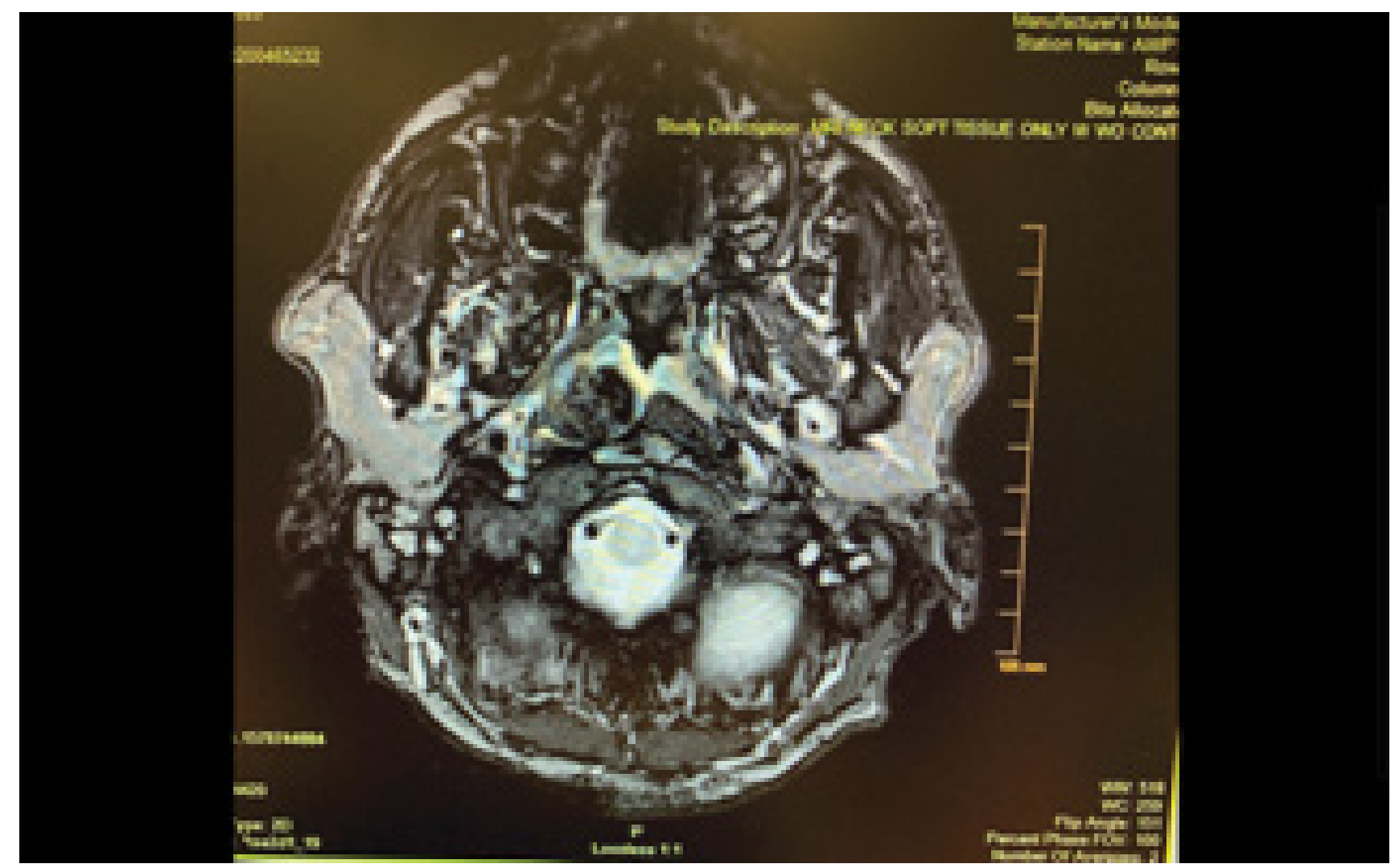

Figure 4: MRI soft tissue neck. Large, right-sided parapharyngeal mass.

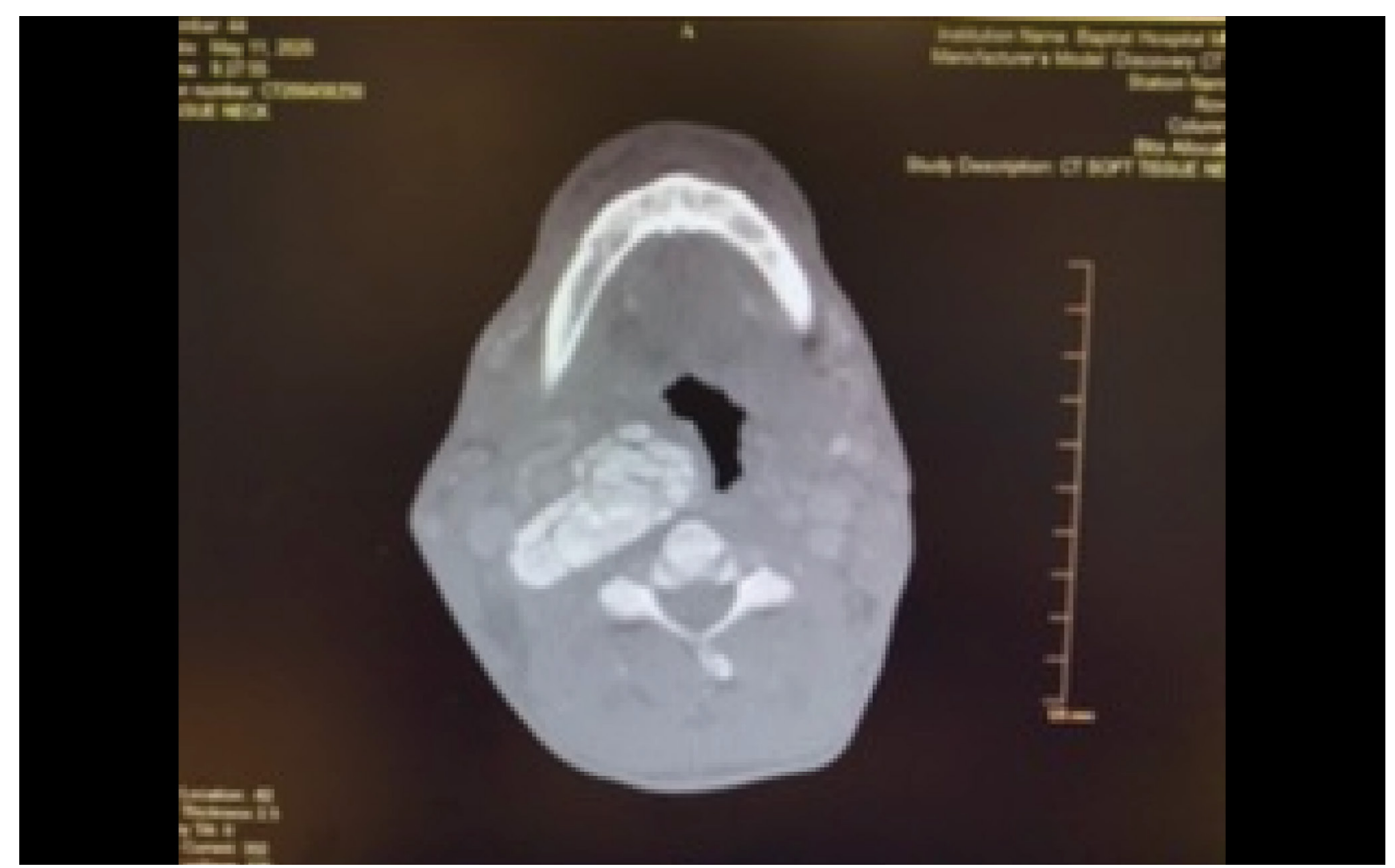

Figure 5: Axial view CT soft tissue neck. Large multilobulated calcified mass. 
explanation for why the calcinosis occurred in the IJV, and nowhere else systemically. More research will be needed into this phenomenon.

\section{Financial Support}

This particular research received no internal or external grant funding.

\section{Conflicts of Interest}

The authors report no relevant financial disclosures related to this current work.

\section{Ethical Considerations}

All issues related to ethics were taken into consideration throughout the study design and proposal and implemented during the research study itself. Informed consent was obtained, beneficence was made a top priority, and respect for confidentiality and privacy were upheld during the study and its various analysis and information assertation components.

\section{Author Contributions}

Theodore Klug, MD, MPH: Collected data, wrote and ed- ited article; Courtney B. Shires, MD, FACS: Collected data, wrote and edited article; Mona Shete, MD: Collected data, wrote and edited article.

\section{References}

1. Binnani P, Aggarwal V, Bahadur MM, et al. (2008) Tumoral calcinosis (Teutschlander disease) in a dialysis patient. Indian J Nephrol 18: 122-124.

2. Jaeger VA, Newman MG, Mirkes CR (2017) Metastatic calcinosis cutis in end-stage renal disease. Proc (Bayl Univ Med Cent) 30: 368-369.

3. Gareth Jones, Edward Kingdon, Paul Sweny, et al. (2003) Tumoral calcinosis and calciphylaxis presenting in a dialysis patient. $\mathrm{Ne}-$ phrology Dialysis Transplantation 18: 2668-2670.

4. Valenzuela A, Chung L (2015) Calcinosis: Pathophysiology and management. Curr Opin Rheumatol 27: 542-548.

5. Westermann L, Isbell LK, Breitenfeldt MK, et al. (2019) Recuperation of severe tumoral calcinosis in a dialysis patient: A case report. World J Clin Cases 7: 4004-4010.

6. Jablonski KL, Chonchol M (2013) Vascular calcification in endstage renal disease. Hemodial Int 17: S17-S21. 